http://dx.doi.org/10.5007/2175-7968.2014v1n33p209

\title{
OS SIMPSONS NO DIA DAS BRUXAS
}

\author{
Chantal Herskovic* \\ Universidade Federal de Minas Gerais
}

\begin{abstract}
Resumo: Este artigo tem como objetivo resgatar paródias da série de TV Os Simpsons a partir de histórias inspiradas em obras da literatura gótica, visando verificar de que forma dialogam com os textos fontes e com o tema de Halloween ou o Dia das Bruxas. Serão utilizadas para análise reflexões teóricas propostas por Umberto Eco (2001) em que o autor discute o papel da cultura de massa na atualidade; por David Punter, (1996) em que analisa as características da literatura gótica; por Alberto Manguel (2005) em que distingue os conceitos de terror e horror; por Julio Plaza (2001) em que propõe estudos sobre transcriação sígnica e o conceito de intertextualidade; e, finalmente, por Linda Hutcheon (1986) em que analisa a questão da adaptação e o conceito de paródia.
\end{abstract}

Palavras-chave: Adaptação. Paródia. Os Simpsons. Terror. Horror.

\section{THE SIMPSONS ON HALLOWEEN}

\begin{abstract}
This article focuses on parodies based on stories in The Simpsons TV series, inspired by Gothic literature, in order to investigate the way such recreations dialogue with the source texts and with the theme of Halloween. The theoretical basis of this article will be Umberto Eco's (2001) reflections on the role of mass culture nowadays; David Punter's
\end{abstract}

\footnotetext{
* Leciona nos cursos de Design e Design Gráfico (UNI-BH). Designer gráfica e ilustradora no Jornal Estado de Minas. Doutoranda em Artes Visuais na Universidade Federal de Minas Gerais (UFMG); Mestre em Artes Visuais (UFMG). Centro Universitário de Belo Horizonte - UNI-BH / Universidade Federal de Minas Gerais - UFMG. Belo Horizonte, Minas Gerais, Brasil. E-mail: chantalh. geo@gmail.com
} 
(1996) analysis of specific features of the Gothic literature; Alberto Manguel's (2005) distinction of the concepts of terror and horror; Julio Plaza's (2001) reflections on signical transcreation and intertextuality; and, finally, Linda Hutcheon's (1986) studies of adaptation and parody. Keywords: Adaptation. Parody. The Simpsons. Terror. Horror.

[...] pedimos que nos contem histórias daquele outro reino de terror e trevas onde tudo é possivel. Alberto Manguel (2005)

A série Os Simpsons tem apresentado, ao longo dos anos, sátiras à sociedade, além de episódios especiais, com mais de vinte programas que remetem a histórias de terror. Inspirados em obras da literatura gótica, em filmes de terror e lendas as mais diversas, esses episódios incluem referências, homenagens e paródias, que estendem o humor próprio da série a limites inimagináveis.

Em Os Simpsons, obras como A Mão do Macaco, de 1902 (MANGUEL, 2005)), Drácula, de 1897 e Frankenstein, de 1818 (cf. SHELLEY, 2001) aparecem referenciadas e recontadas, portanto, parodiadas, através dos personagens amarelos de Matt Groening, especialmente associadas à tradição do Dia das Bruxas. O primeiro desses episódios consistiu em uma adaptação do conto de Edgar Alan Poe, O Corvo, de 1845, "The Raven” ( POE, 2011), narrado pela voz de Homer Simpson e representado através de imagens animadas, que brincam com os elementos da obra literária. Aliás, uma das características da série é o jogo de referências cruzadas com outras obras da literatura, do cinema e da própria televisão - como outros desenhos animados e seriados.

Muitas obras de horror da literatura foram referenciadas nestes últimos vinte e dois anos em Os Simpsons, incluindo textos de autores como Edgar Alan Poe, Mary Shelley, e Bram Stoker ${ }^{1}$. Da mesma forma, foram homenageados e satirizados diretores de cinema, como Stanley Kubrick e Wes Craven². Eco (2001) em Apoca- 
lípticos e integrados discute o papel da cultura de massa como entretenimento e meio privilegiado para difundir um enorme acervo de conhecimento sem promover quaisquer discriminações e sendo capaz de sensibilizar o homem contemporâneo em relação à arte, a toda uma tradição cultural.

Uma festa tradicional nos Estados Unidos, Halloween, ou o Dia das Bruxas, celebrada no mês de outubro, será o elemento de aproximação entre os personagens da série Os Simpsons e tantas obras góticas reconhecidas por seu valor artístico, aludidas nos episódios. Tida como uma celebração do calendário celta - Samhain - que marca o fim do verão, esse Dia das Bruxas ocupa um lugar especial na série, desde a segunda temporada. O primeiro episódio temático intitulou-se, no Brasil, No Dia das Bruxas (1990), tornando-se mais tarde A Casa do Horror III (1992). Logo após, em 1993, adotou-se uma tradução mais próxima do nome em inglês A casa da árvore dos horrores (Treehouse of Horror), já com vinte e dois episódios (vigésima - terceira temporada, 2011-2012).

Inicialmente, o especial era apresentado por um dos personagens da série, Marge Simpson, mãe da família, que sempre advertia que a comemoração do Dia das Bruxas era aterrorizante; por isso, as crianças não deveriam assisti-la. Os produtores, por estarem temerosos de receber críticas dos espectadores, acharam melhor colocar um aviso destinado aos pais quanto a algumas restrições do programa. Contudo, $\log$ o perceberam que esses episódios não eram tão perturbadores assim, mas continuaram colocando elementos macabros e violentos, na abertura, para alertar a audiência quanto ao conteúdo a ser apresentado. Pastiche de quadros como $O$ Grito de Munch (de 1893) e A Friend in Need (de 1903, Brown \& Bigelow) de Cassius Coolidge já foram incluídos nessas aberturas; ou ainda, passagens pelas tumbas de um cemitério, ao invés da tradicional visão panorâmica da cidade.

Houve, inclusive, episódios em que se parodiou a série $O s$ Monstros (1964-1966) ${ }^{3}$ e Contos da Cripta (1989-1996) ${ }^{4}$. Houve também festas celebradas no Dia das Bruxas, que acabariam em 
morte, trazendo situações violentas, como a que o Reverendo Lovejoy queima as irmãs bruxas de Marge, Patty e Selma, em uma estaca, numa alusão que se pode fazer às Bruxas de Salém, 1953, peça do autor norte-americano Arthur Miller5. Todos esses temas de barbárie e perseguição, em que prevalece o medo do demônio e dos maus espíritos, remontam inclusive ao período da Inquisição, em que a tortura e a morte na fogueira eram incutidas às pessoas tidas como bruxas.

Nesses episódios especiais, os personagens, de fato, podem morrer ou incorporar a própria morte com uma foice ${ }^{6}$, subir ao céu e descer ao inferno, discutir com o diabo (que pode até ser Ned Flanders) ${ }^{7}$ ou se tornar bruxas e $\operatorname{sapos}^{8}$. Podem ir a Salém ou voltar de lá ou, ainda, os mortos podem ser capazes de caminhar novamente sobre a terra ${ }^{9}$. Não há, portanto, quaisquer restrições, e os próprios nomes dos criadores, roteiristas, dubladores e produtores aparecem de forma diferente nos créditos iniciais e finais, com brincadeiras com seus nomes como "Bat" Groening ao invés de Matt Groening, para citar um exemplo, o que ocorre em todos os episódios especiais de dia das bruxas da série.

Um eixo importante de referência para Os Simpsons encontra-se, ainda, na literatura gótica, em inúmeros intertextos e paródias a obras que, no século XIX, eram consideradas populares, publicadas em folhetins, revistas, jornais e livros de baixo custo. Segundo David Punter em The literature of terror (1996), nas histórias góticas há elementos característicos do gênero e que se repetem, como cenários e personagens medievais, incluindo: castelos, florestas encantadas, ruínas, viagens a lugares desconhecidos, cavaleiros, donzelas, criaturas fantásticas, monstros, objetos mágicos, oriundos de lugares remotos; ou ainda, segredos do passado, manuscritos escondidos, profecias e maldições, além de elementos demoníacos, satânicos, bestiais, macabros, envolvendo crueldade, sadismo, e a personificação do mal.

Cabe, então, conceituar terror e horror, segundo os Contos de horror do século XIX, de Alberto Manguel: 
O terror e o horror possuem características tão claramente opostas, que um dilata a alma e suscita uma atividade intensa de todas as nossas faculdades, enquanto o outro as contrai, congela-as, e de alguma maneira as aniquila. Nem Shakespeare nem Milton em suas ficções, nem Mr. Burke em suas reflexões, buscaram no horror puro uma das fontes do sublime, embora reconhecessem que o terror é uma das causas mais elevadas do sublime. Onde situar, então, essa importante diferença entre terror e horror senão no fato de que este último se faz acompanhar de um sentimento de obscura incerteza em relação ao mal que tanto teme. (MANGUEL, 2005, p. 10-11).

O horror, portanto, é aquilo que causa aversão, que faz com que o leitor ou espectador evite olhar ou imaginar alguma coisa, como cenas de tortura. Já o terror remete a impressões, ao suspense, ao medo do desconhecido, muitas vezes causado por ruídos diversos, especialmente sons guturais, batidas na porta, passos, correntes que se arrastam, armários que rangem, espelhos que se quebram, dentre outros. Ou seja, o terror é a antecipação e o horror a realização de algo que se temia acontecer, sendo que ambos os conceitos vão aparecendo, nos episódios de Os Simpsons, ao longo das temporadas.

Uma das histórias de terror que tem feito sucesso é o episódio A casa da árvore dos horrores XVII (2006), $14^{\mathrm{a}}$ temporada, associado à lenda do Golem, termo que, no folclore judaico, significa "informe". A mais conhecida história do Golem é a do Rabino Judá Loew Ben Bezalel, de Praga (UNTERMAN, 1992, p.107), também chamado simplesmente o Golem de Praga, que remonta ao final do século XVI. De acordo com a narrativa infundada e promotora do antissemitismo, os judeus teriam sido acusados de haverem matado crianças para, com o seu sangue, fazerem o pão da Páscoa judaica (matzá). A população de Praga procurou invadir o gueto para matar seus ocupantes e, para defendê-los, o rabino teria chamado o Golem, homem criado a partir da magia cabalística. 
Na paródia de Os Simpsons, Krusty, o palhaço, é o proprietário do Golem de Praga. Fisicamente, aparece com uma caricatura do personagem retratado pelo diretor de cinema Paul Wergener no filme Der Golem, de 1920. Esse episódio, portanto, é uma homenagem à lenda do Golem, que alude, por sua vez, à perseguição aos judeus, sem deixar de incluir referências à cultura e ao humor judaico.

Ao se fazer referência à galeria de textos parodiados, não poderia faltar $A$ mão do macaco, de 1902, (MANGUEL, 2005) de W. W. Jacobs, no episódio do Dia das Bruxas II (1991). O conto de Jacobs narra a chegada, à casa da família White, de uma mão mumificada, que teria o poder de realizar os desejos de três pessoas, cada uma delas com direito a três pedidos.

No episódio de animação, a família White, inglesa, composta de pai, mãe e um rapaz, recebe a visita de um sargento, recém-chegado da Índia, que lhes conta suas aventuras e mostra a mão de um macaco, que logo resolve destruir, atirando-a ao fogo. O Sr. White rapidamente a retira do fogo, pedindo para ficar com ela, mas o sargento, que encarna a figura arquetípica de um velho e sábio conselheiro, aconselha-o a deixá-la queimar:

Possui o encantamento que lhe foi conferido por um velho faquir", disse o sargento. "Um homem muito santo. Ele queria mostrar que o destino rege a vida das pessoas e que aqueles que interferem nele correm o risco de se arrepender amargamente. (MANGUEL, 2005, p.16).

A família não acredita na história que ouve e o Sr. White faz um pedido àquela mão, o que acaba lhes trazendo desgraça quando, em seguida, o jovem rapaz morre preso a uma máquina. Sutilmente, há uma menção à Revolução Industrial e aos horrores que, na época, ela teria causado à comunidade, como mortes desse tipo. Ao longo da história, percebe-se que a mão mágica brinca com os desejos dos homens, atende-os de forma sórdida e irônica. Observou-se, 
na realidade, que a literatura gótica explora o medo da Revolução Industrial e o uso indiscriminado das máquinas, sendo esses temas, frequentemente, explorados na mídia.

Filmes com temas afins são o Exterminador do Futuro (1984, direção de James Cameron) e 2001: Uma Odisseia no Espaço (de Stanley Kubrick). Neles, aparecem questões como o terrorismo e a guerra biológica, bem como o medo das armas contemporâneas, da tecnologia digital, do mundo virtual, do poder da comunicação via satélite ou até por telefones celulares. Tal como ocorre em 2001: Uma Odisseia no Espaço, no episódio do Dia das Bruxas, $A$ casa na árvore dos horrores XII, da $11^{\text {a }}$ temporada (1999), Marge transforma a residência familiar em uma casa robotizada de última geração. Um robô comanda todo o funcionamento, com a voz emprestada de Pierce Brosnam. A imagem do robô é um pastiche de Hal, do filme de Stanley Kubrick, que fica igualmente fora de controle. Apaixona-se por Marge e tenta assassinar Homer, que sobrevive e o desativa, assim como faz o astronauta no filme. Mais uma vez, a tecnologia desempenha o papel de vilã da história.

Numa teia de intertextualidade em que romances, filmes, músicas e episódios de animação dialogam, o que se observa é uma verdadeira transcriação sígnica; uma transcriação de formas, em que signos vindos de suportes, meios e fontes diversas se entrelaçam e acabam por iluminar-se entre si (PLAZA, 2001). Nessa teia de remissões, destaca-se a figura do macaco assassino, que reaparece em Os Simpsons. O livro Assassinatos na Rua Morgue, de 1841, de Edgar Alan Poe (2002), em que o criminoso é um gorila, encontra-se nessa sintonia e pode remeter à figura do King Kong ${ }^{10}$ (1933), criado por Edgar Wallace (1875-1932), que morreu antes de terminar o seu texto. King Kong também foi parodiado pela série Os Simpsons, no especial do Dia das Bruxas, A Casa do Horror III (1992), em que Homer encarna esse personagem. Mas, ao invés da história se passar em Nova York, acontece, é claro, em Springfield.

Jean Chevalier e Alain Gheerbrant, em Dicionário de Símbolos (2000), abordam a simbologia do macaco, em muitas culturas. 
Esse animal é, muitas vezes, mostrado como um sábio, um iniciado, capaz de transcender; um ser que esconde a sua inteligência para testar, de alguma maneira, o homem. Associado à ascensão espiritual e também visto como um guia, a figura do macaco, na roda da existência tibetana, significa consciência, mas de forma pejorativa. Dentro dessa filosofia, a consciência do homem ou o seu lado sensível estaria sendo visto como inconstante, sempre pulando de um objeto a outro; tal como o macaco pula de galho em galho. Considerado um Bodhisattva, este aspecto da simbologia do macaco faz parte da mitologia budista, em que seria um ser de sabedoria elevada, comprometido com uma prática espiritual, ou também, um mágico Taoísta de grande envergadura. Na Índia, há também o mito de Hanumam Ramayana, o macaco real e o Rei-macaco Suen Hingtchö, que consegue alcançar o estado de Buda. No extremo oriente, a figura do macaco está relacionada à sabedoria, ao desprendimento e um exemplo disso são os três macacos do Jingoro, em que um tampa os ouvidos, o outro tampa os olhos e o último, a boca.

$\mathrm{Na}$ literatura gótica, há criaturas que vêm de lugares distantes, como Drácula, proveniente da Romênia, e a Criatura de Frankenstein, que leva seu criador para o Pólo Norte. Quanto à mão de macaco mumificada, ela teria sua origem na Índia, como é relatado no conto de W. W. Jacobs (MANGUEL, 2005). Em Os Simpsons, os macacos são representados, com frequência, pulando de um lugar a outro, sem o dom da fala. Mas há também os macacos que falam, como o Mr. Teeny, o ajudante de Krusty o palhaço, o qual tem a sua própria língua para se comunicar e que chega até o espectador através da tradução. Há muitas brincadeiras e gags, como no episódio $O$ Sr. Burns está amando $(2001)^{11}$ que aparece uma fábrica de biscoitos da sorte em que os bilhetinhos contidos na guloseima são escritos por macacos acorrentados às máquinas de escrever, numa gag sobre a exploração dos escritores e roteiristas. Já no episódio Homer Astronauta (1994) da quinta temporada, os cientistas da NASA se perguntam se deveriam contar à população que todos os macacos enviados ao espaço voltaram extremamente inteligentes. 
Mas um tema que tem, sobremaneira, apelado à imaginação é o das casas macabras, aparecendo no cinema como: a história da casa de Connecticut em Evocando Espíritos (A Haunting in Connecticut - EUA - 2009), dirigida por Peter Cornwell; um documentário do Discovery Channel dirigido por John Kavanaugh A Haunting In Connecticut de 2002; a casa de Amityville, que ganhou versões no cinema e refilmagens inspiradas no livro The Amityville Horror: A True Story publicado em 1977, de Jay Anson; O Exorcista (1973), dirigido por William Friedkin, adaptado do livro de William Peter Blatty de 1971 (BLATTY, 2013); e a série Poltergeist escrita por Steven Spielberg, com o primeiro filme Poltergeist, o fenômeno lançado em 1982, dentre outros.

Em Os Simpsons, há episódios que se referem aos filmes Poltergeist e $O$ Exorcista, principalmente no episódio No Dia das Bruxas, o qual remete a estes dois filmes e a Horror em Amityville. O episódio de animação começa com Homer chegando à sua casa fantasiado de fantasma após ganhar alguns doces. Ele percebe que as crianças estão na casa da árvore contando histórias de terror e horror; então, se aproxima para escutar, sem ser visto. A primeira história é sobre uma casa maldita com o segmento intitulado $A$ casa do pesadelo.

A imagem da casa, no alto da colina, é similar àquela em vivia Norman Bates, o assassino de Psicose (1960), dirigido por Alfred Hitchcock. Porém, quando vista de lado, a casa possui o mesmo formato do celeiro da casa de Horror em Amityville (1979); portanto, é feita uma referência cruzada a ambas as casas. Os Simpsons acabam de se mudar para ali e vários objetos começam a flutuar pela casa, sem que percebam. As paredes da cozinha sangram como no filme Horror em Amytville.

Em $A$ casa do pesadelo, Marge, inicialmente, se recusa a ficar ali por ser uma casa maligna, mas também esta, ironicamente, prefere se implodir a viver com os Simpsons, tal como a casa de $A$ Queda da casa de Usher (1839) de Edgar Alan Poe (2008). Enfim, este episódio faz gags com elementos comumente encontrados em 
histórias de casas mal assombradas, como objetos voando, sangue jorrando e vozes sinistras. A estrutura da narrativa também é similar a tantas outras histórias, como aquela em que uma família acaba de se mudar para uma casa, por algum motivo, e, logo eles percebem manifestações macabras. No episódio No Dia das Bruxas a casa para a qual os Simpsons se mudam fora construída em cima de um cemitério indígena.

Os personagens góticos transitam, portanto, por locais macabros, com ruídos estranhos, indagando a si próprios sobre a sua própria loucura, sobre seus receios e dores, como o personagem Renfield em Drácula de Bram Stoker. Assim, o vampiro é outro ser sobrenatural que povoa as histórias de terror e horror e, no quarto episódio do Dia das Bruxas, $A$ casa da árvore dos horrores IV (1993), a série faz uma paródia à história de Drácula. Drácula de Bart Simpson faz uma apologia ao filme Drácula de Bram Stoker (1992) de Francis Ford Coppola e ao livro de Bram Stoker, publicado em 1897 (SHELLEY, 2001).

O vampiro é um morto-vivo que abandona o seu túmulo e vai se alimentar de sangue. Sua lenda difundiu-se pela Rússia, Polônia, na Europa central, na Grécia e na Arábia. Segundo essa lenda, se alguém é mordido por um vampiro ou bebe o seu sangue, transforma-se também em outro vampiro. Essa lenda está ligada a questões existenciais, como a imortalidade da alma e, segundo Stephen King em seu livro Dança Macabra (2003), trata-se do tema mais comum na literatura do fantástico.

A figura do vampiro também está relacionada aos morcegos e aos ratos, pois, Drácula, na obra de Bram Stoker, quando chega a Londres, leva a Peste Negra, outra questão que preocupava as pessoas da Idade Média e também um elemento dos contos góticos. Frankenstein de Mary Shelley faz menção a essa peste, pois a cidade onde Victor Frankenstein faz suas experiências sofre um surto de tal praga.

No episódio de 1993, Casa do Horror III, Burns é uma caricatura de Drácula. Os Simpsons são convidados para jantar em seu castelo na Pensilvânia (o de Drácula fica na Transilvânia). Porém, 
Bart é mordido e há um close dele na janela, que remete à história de Stephen King (2010), A hora do vampiro, de 1975. Outra referência de vampiros, na janela, chamando os vivos, encontra-se no conto gótico $A$ família do vurdalak de Aleksei Konstantinovitch Tolstoi, de 1839, (cf. MANGUEL, 2005).

No início do episódio que dialoga com esse tema, a família Simpson assiste a um noticiário que avisa que mais um corpo fora encontrado e não havia uma gota de sangue sequer nele. Do mesmo modo, a tripulação do navio que levava Drácula para Londres ia desaparecendo, ou as pessoas apareciam mortas, mas sem qualquer mancha de sangue. Junto aos corpos, em Springfield, houve até um momento em que foi achada uma capa preta com o nome de Drácula marcado.

Já a cena de Bart e Lisa, no porão com os caixões, remete a uma cena similar do filme de Roman Polanski, A Dança dos Vampiros (1967). O episódio explora esses elementos de forma a provocar o humor e o espectador que, familiarizado com tais motivos recorrentes, poderá perceber referências cruzadas em relação às clássicas histórias de terror e horror, em que aparecem vampiros, que envolvem castelos e ambientes sombrios.

As histórias dos vampiros se popularizaram com Drácula, porém, nos anos 1970, e especialmente no início do século XX, algumas histórias trouxeram para o mainstream o conto do vampiro, como é o caso dos filmes Os garotos perdidos (1987), Vampiros de John Carpenter ${ }^{12}$ (1998), Um Drink no Inferno (1996) e das obras da escritora Anne Rice ${ }^{13}$, conhecida por seus livros com personagens vampirescos e ao estilo do monstro Frankenstein.

Uma das histórias mais notórias da literatura gótica, assim como Drácula, é a do Prometeu Moderno, como também é conhecida a obra Frankenstein. A obra escrita por Mary Shelley e publicada em 1818, conta a história de Victor Frankenstein, estudante de ciências naturais que conseguiu criar um monstro. A criatura, como é chamada na obra, foi construída a partir de partes de cadáveres, tendo sido animado por correntes elétricas. 
Não há nenhuma preocupação ética na história, havendo certa visão negativa da tecnologia, pois a sede pelo conhecimento acaba levando o cientista a criar um monstro destituído de moralidade. $\mathrm{O}$ monstro vai contra o ciclo normal da vida, de nascer e morrer; ele já está morto e volta a viver, ou seja, um estado que vai contra a natureza. Depois de criado o monstro, Victor Frankenstein, o cientista, reflete sobre o que havia construído e este é o seu primeiro pensamento em relação à criatura:

\begin{abstract}
Ai, de mim! Libertara no mundo uma criatura vil que encontrava prazer nos massacres e na infelicidade alheia; pois não tinha assassinado meu irmão?

Ninguém seria capaz de imaginar a angústia que senti durante o restante da noite - que passei, molhado e com frio, ao relento. Não senti, porém, as inconveniências do tempo; minha imaginação estava tomada de cenas de maldade e desespero. Pensei no ser que lançara entre os homens e que dotara do poder e da determinação de levar a cabo propósitos nefandos, como aquele que acabar de perpetrar, como se fosse meu próprio fantasma, meu próprio espírito libertado de sua cova e forçado a destruir tudo o que me era querido. (SHELLEY, 2001, p.88).
\end{abstract}

Mais uma vez, Frankenstein pensa, acima de tudo, em si mesmo, se concentra mais no seu próprio microcosmo do que no macrocosmo. E, além disso, a criatura que o cientista tinha sido capaz de produzir era dotada da capacidade de pensar e de refletir. O fato é que o cientista se deixara levar pela vaidade de criar um homem e, em um determinado momento, vê-se o monstro questionar sobre o seu criador e lhe falar sobre moral, ética e compaixão. São os homens que o perseguem, que o maltratam e este acaba por querer vingar-se deles, incluindo o próprio criador: 
'Odioso foi o dia em que recebi a vida!', exclamei, em minha agonia. 'Maldito criador! Por que fez de mim um monstro tão hediondo de quem até mesmo você se afastou, com aversão? Deus, em sua piedade, fez os homens belos e encantadores, à Sua própria imagem; meu aspecto, porém, é uma representação asquerosa do seu, e a mínima semelhança torna-o ainda mais horrendo. Satã tinha seus companheiros, outros demônios, para admirá-lo e encorajá-lo, porém, eu sou solitário e abominado.' (SHELLEY, 2001, p.139).

Os propósitos de Frankenstein tinham sido, portanto, egoístas, apesar de acreditar que sua pesquisa era importante para a humanidade. Finalmente, o terceiro segmento do Dia das Bruxas II, terceira temporada (1991), também remete à história de Frankenstein e, assim, a tecnologia ocupa um lugar central no enredo do episódio. Nesse último, a criatura é um robô, que precisa de um cérebro para viver. A série de Os Simpsons faz, portanto, referência ao elemento principal na construção da criatura de Frankenstein, que é o cérebro roubado. Outro traço do conto de Mary Shelley no episódio é a forma como o cientista dá vida à criatura, utilizando-se de ondas elétricas.

Ficou claro que a intertextualidade é uma das principais características dessa série animada. Ela cria um pacto com o espectador, no momento em que este é capaz de perceber as referências a tantas outras obras, na literatura, no cinema, nos quadrinhos, na música... Há, pelo menos, dois tipos de espectadores que apreciam Os Simpsons: aquele que reconhece as obras citadas ou aludidas, direta ou indiretamente, e poderá fazer as ligações intertextuais necessárias; e há, ainda, o espectador "ingênuo", que assiste o que lhe é apresentado, embora seja capaz de reconhecer elementos recorrentes sobre a temática do terror e do horror.

A análise dos episódios de Os Simpsons associados ao Dia das Bruxas demonstra que, tal como frequentemente ocorre na arte contemporânea, essas narrativas fílmicas valem-se de alusões, re- 
ferências, releituras ou reciclagem de tantas outras obras; estas podem pertencer, portanto, a outros sistemas semióticos, relacionadas à literatura de terror ou de horror, ao gênero gótico. Nesse sentido, possibilitam sempre releituras passíveis de vários níveis de interpretação, a depender do repertório cultural e da recepção personalizada dos espectadores envolvidos.

\section{Notas}

1. No dia das bruxas (1990 - EUA), dirigido por David Silverman; No dia das bruxas II ( 1991 - EUA), dirigido por Jim Rondon Reardon; e $A$ casa da árvore dos horrores IV (1993 - EUA), dirigido por David "Dry Bones" Silverman, respectivamente.

2. Criador da série Hora do pesadelo, Pânico, Eu sei o que vocês fizeram no verão passado dentre outros.

3. A casa da árvore dos horrores XI (2000 - EUA), dirigido por Matthew Nastuk.

4. A casa da árvore dos horrores XVII (2006 - EUA), dirigido por David "Tubatron" Silverman Malicious Matthew C. Faughnan.

5. A casa da árvore dos horrores V (1994 - EUA), dirigido por Jaundiced Jim Reardon.

6. A casa da árvore dos horrores XIV (2003 - EUA), dirigido por Steve Dean Morbid.

7. A casa da árvore dos horrores IV (1993 - EUA), dirigido por David "Dry Bones" Silverman. 
8. A casa da árvore dos horrores VIII (1997 - EUA), dirigido por Mark Kirkland.

9. A Casa do Horror III (1992 - EUA), dirigido por Bloodcurdling Carlos Baeza.

10. King Kong (EUA - 1933), direção de Merian C. Cooper e Ernest B. Schoedsack.

11. O Sr. Burns está amando (Hunka Hunka Burns in Love - 2001 - EUA), dirigido por Lance Kramer.

12. John Carpenter é um dos diretores conhecidos por seus filmes de terror e horror, e criador da série de filmes Halloween.

13. Algumas obras da escritora norte-americana foram adaptadas para o cinema, como Entrevista com Vampiro e Rainha dos Condenados. Anne Rice, nos anos 1970, com seu livro Entrevista com Vampiro, criou uma série de romances vampirescos como o Ladrão de Corpos, Lestat, Rainha dos Condenados, dentre outros e sua série As Crônicas Vampirescas. Também escreveu sobre as bruxas em seus livros A Hora das Bruxas e suas sequências, tendo Nova Orleans, cidade onde mora, como o cenário da maior parte de seus romances, pois é cheia de histórias e lendas de fantasmas e vodus.

\section{Filmografia sugerida}

A dança dos vampiros (The Fearless Vampire Killers - Inglaterra - 1967), direção de Roman Polanski.

A Haunting In Connecticut (EUA - 2002), direção de John Kavanaugh.

Evocando Espíritos (A Haunting in Connecticut - EUA - 2009), direção de Peter Cornwell.

Horror em Amityville (The Amityville Horror - EUA - 1979), direção de Stuart Rosenberg. 
King Kong (EUA - 1033), direção de Merian C.Cooper e Ernest B. Schoedsack.

Os garotos perdidos (The Lost Boys - EUA - 1987), direção de Joel Schumacher.

O Iluminado (The Shining - EUA - 1980), direção de Stanley Kubrick.

Poltergeist, o fenômeno (Poltergeist - EUA - 1982), direção de Tobe Hooper.

Psicose (Psycho - EUA - 1960), direção de Alfred Hitchcock.

Um Drink no Inferno (From Dusk Till Dawn - EUA - 1996), direção de Robert Rodriguez.

Vampiros de John Carpenter (Vampires - EUA - 1998), direção de John Carpenter.

\section{Episódios da série Os Simpsons}

No dia das bruxas (1990 - EUA), dirigido por David Silverman.

Dia das bruxas II ( 1991 - EUA), dirigido por Jim Rondon Reardon.

A Casa do Horror III (1992 - EUA), dirigido por Bloodcurdling Carlos Baeza.

A casa da árvore dos horrores IV (1993 - EUA), dirigido por David "Dry Bones" Silverman.

A casa da árvore dos horrores V (1994 - EUA), dirigido por Jaundiced Jim Reardon.

A casa da árvore dos horrores VI (1995 - EUA), dirigido por Mike B. Anderson.

A casa da árvore dos horrores VII (1996 - EUA), dirigido por Bob Anderson. 
A casa da árvore dos horrores VIII (1997 - EUA), dirigido por Mark Kirkland.

A casa da árvore dos horrores X (1999 - EUA), dirigido por Pete "Scary Spice" Michels.

A casa da árvore dos horrores XI (2000 - EUA), dirigido por Matthew Nastuk.

A casa da árvore dos horrores XIV (2003 - EUA), dirigido por Steve Dean Morbid.

A casa da árvore dos horrores XVII (2006 - EUA), dirigido por David "Tubatron" Silverman e Malicious Matthew C. Faughnan.

Bart Has Two Mommies (2006 - EUA), dirigido por Michael Marcantel.

Chamando os Simpsons (1990 - EUA), dirigido por Wes Archer.

Girly Edition (1998 - EUA), dirigido por Mark Kirkland.

Homer Astronauta (1994 - EUA), dirigido por Carlos Baeza.

O Sr. Burns está amando (2001 - EUA), dirigido por Lance Kramer.

Realty Bites (1997 - EUA), dirigido por Swinton Scott.

\section{Referências}

ANSON, Jay. The Amityville Horror: A True Story. Upper Saddle River: Prentice Hall, 1977. 
BLATTY, William Peter. O Exorcista. Rio de Janeiro: Nova Fronteira, 2013.

CHEVALIER, Jean; GHEERBRANT, Alain. Dicionário de Símbolos. Rio de Janeiro: José Olympio, 2000.

ECO, Umberto. Apocalípticos e integrados. São Paulo: Perspectiva, 2001.

GIMPLE, Scott M. (Ed.). The Simpsons forever: A complete guide to our favorite family... continued. Nova York: Harper Perennial, 1999.

HERSKOVIC, Chantal. Chegando em Springfield: um estudo crítico sobre a série "Os Simpsons". Dissertação (Mestrado em Artes Visuais)- Escola de Belas-Artes, Universidade Federal de Minas Gerais, Belo Horizonte, 2005.

HUTCHEON, Linda. A theory of parody. The teachings of twentieth-century art forms. Nova York: Methuen, 1986.

KING, Stephen. A hora do vampiro. Rio de Janeiro: Objetiva, 2010.

KING, Stephen. Dança Macabra. Rio de Janeiro: Objetiva, 2003.

MANGUEL, Alberto (Org). Contos de Horror do século XIX. São Paulo: Companhia das Letras, 2005.

MCCANN, Jesse L. (Ed.). The Simpsons Beyond Forever: a complete guide to our favorite family... still continued. Nova York: Harper Perennial, 2002.

PLAZA, Julio. Tradução intersemiótica. São Paulo: Perspectiva, 2001.

POE, Edgar Alan. Os assassinatos da rua Morgue. Porto Alegre: L\&PM, 2002.

POE, Edgar Alan. The Raven and Other Stories. San Diego: IDW Publishing, 2011. 
POE, Edgar Alan. Histórias Extraordinárias. São Paulo: Companhia das Letras, 2008.

PUNTER, David. The Literature of terror: a history of gothic fictions from 1765 to the present day. Harlow: Longman House, 1996.

RICHMOND, Ray; COFFMAN, Antonia (Ed.). The Simpsons: a complete guide to our favorite family. Nova York: Harper Perennial, 1997.

SHELLEY, Mary Wollstonecraft. Frankenstein / Mary Shelley, Dracula / Bram Stocker, Dr. Jekyll and Mr. Hyde / Robert Louis Stenevson. Rio de Janeiro: Ediouro, 2001.

UNTERMAN, Alan. Dicionário judaico de lendas e tradições. São Paulo: Jorge Zahar, 1992.

Recebido em: 15/01/2014 Aceito em: 29/04/2014 
